\title{
Update on NSCLC tissue acquisition, processing, and profiling in the molecular age
}

\author{
Anna J. Conterato ${ }^{1}$, Adam R. Belanger ${ }^{1}$, Lonny B. Yarmus ${ }^{2}$ and Jason A. Akulian ${ }^{1 *}$ \\ ${ }^{1}$ Section of Interventional Pulmonology, Division of Pulmonary and Critical Care, University of North Carolina in Chapel Hill, USA \\ ${ }^{2}$ Section of Interventional Pulmonology, Division of Pulmonary and Critical Care, Johns Hopkins University, USA
}

\begin{abstract}
As novel therapies for specific genetic mutations, chromosomal rearrangement profiles and check point inhibition in patients with NSCLC becomes more ubiquitous, adequate tissue acquisition and specimen processing has become crucial. Historically, tissue was obtained via invasive surgical resection or sampling. New tissue acquisition techniques have become increasingly commonplace in the diagnosis of NSCLC; these techniques are less invasive and at least equally reliable, if not superior, at obtaining tissue for diagnosis and molecular profiling. The preparation of tissue specimens has also been the subject of study as different methods have shown to increase cellular yield. This is of particular importance as the number of clinically significant targetable mutations and chromosomal rearrangements continues to grow, next generation sequencing becomes increasingly commonplace, and the need for more tissue increases.
\end{abstract}

\section{Introduction}

Lung cancer remains the most common cause of cancer death in the United States and will likely account for more than 150,000 deaths in 2016. This is more than breast, colon, and prostate cancer combined. Additionally, it is projected that more than 220,000 new cases of lung cancer will be diagnosed in 2016 . The incidence and overall mortality from lung cancer is noted to be increasingly borne by women [1].

There have been several significant advances in the treatment of non-small cell lung cancer (NSCLC) in the last several years, advances which require careful biopsy sample acquisition and processing. Specifically, specimens must be adequate to permit molecular profiling to search for driver mutations and determine if targeted therapies, rather than standard cytotoxic chemotherapy alone, are indicated [2]. KRAS, EGRF and AML4-ALK are the most common molecular markers for which testing is recommended [3]. In addition to targetable mutations, immune checkpoint inhibitors (PD-L and PD-L1) have the potential to revolutionize the treatment of lung cancer $[4,5]$.

Given the importance of tissue analysis and processing, safe and efficient tissue acquisition has been recommended by the Study of Lung Cancer/American Thoracic Society/European Respiratory Society International Multidisciplinary Classification of Lung Adenocarcinoma guideline [6]. Tissue samples should be sufficient to identify targetable mutations and immune checkpoint inhibitors, so as to direct therapy for patients with advanced lung adenocarcinoma. This review will focus on squamous cell cancer (SCC), adenocarcinoma, and NSCLC not otherwise specified (NSCLC-NOS), with emphasis on relevant molecular markers and immune checkpoint inhibitors, their acquisition, and processing.

\section{Tissue acquisition}

\section{Surgical methods}

Historically, tissue acquisition for the diagnosis and staging of NSCLC was accomplished via surgical means, namely mediastinoscopy and video assisted thoracoscopic surgery (VATS) [7-10]. While these techniques have an excellent track record and allow for large sample sizes, they are invasive procedures with non-negligible associated morbidity and mortality and are often performed on patients with advanced NSCLC who are ultimately not candidates for definitive surgical resection.

Mediastinoscopy: Mediastinoscopy requires general anesthesia, with the patient prepped for an emergent sternotomy in the event of vascular complications. The surgeon begins the procedure by making a small incision just superior to the sternal notch; this is followed by blunt dissection of the tissue planes into the mediastinum. Once the mediastinum has been accessed, lymph node stations, 2 (upper paratracheal), 3a (pre-vascular), 4 (lower paratracheal) and 7 (subcarinal), as well as medial portions of station 1 (high mediastinum) can be sampled. This allows acquisition and assessment of tissue at the $\mathrm{N} 2$ and N3 levels. While mediastinoscopy is considered an outpatient procedure, it does carry a real risk of morbidity and mortality $(2 \%$ and $0.8 \%$, respectively). Complications of mediastinoscopy include recurrent laryngeal nerve injury, hemorrhage, tracheal injury, and pneumothorax [11]. Another drawback to the procedure is that N1 and parenchymal tissue cannot be assessed. Additionally, initial staging with mediastinoscopy for likely $\mathrm{N} 2$ disease may make a re-staging mediastinoscopy following neo-adjuvant chemotherapy and radiation

Correspondence to: Jason A. Akulian, Director, Interventional Pulmonology, Assistant Professor of Medicine, Division of Pulmonary and Critical Care Medicine, University of North Carolina at Chapel Hill, Chapel Hill, NC 27599, USA, Tel: 919-966-2551; Fax: 919-966-7013; E-mail: jason_akulian@med.unc.edu

Key words: lung cancer, non-small cell lung cancer (NSCLC), mediastinal staging, lymph node, endobronchial ultrasound (EBUS), epidermal growth factor receptor (EGFR), bronchoscopy

Received: February 22, 2017; Accepted: March 09, 2017; Published: March 11, 2017 
technically challenging [12].

Video-Assisted Thoracoscopic Surgery (VATS): VATS require general anesthesia, but unlike mediastinoscopy, the procedure requires single lung ventilation for the majority of the procedure. Some patients are unable to tolerate single lung ventilation precluding the use of VATS. Access to the pleural space is obtained through three to four surgical ports placed via small incisions. One port is dedicated to the camera and allows the surgeons to direct their surgical tools, which are placed through the other ports in a triangular configuration. VATs be used to determine $\mathrm{T}$ stage, limited $\mathrm{N}$ staging and may identify occult pleural disease (M1a staging) through direct visualization and biopsy of the thoracic cavity. The risk of morbidity is similar to that of mediastinoscopy, though the procedure does require chest tube placement post-procedure and admission to the hospital [8] One of the major limitations of VATS is its unilateral nature. Should disease be suspected on the contralateral side, a second invasive procedure may be required.

\section{Bronchoscopic techniques}

\section{Endobronchial Ultrasound Guided Transbronchial Needle Aspiration (EBUS-TBNA)}

EBUS-TBNA has revolutionized the diagnosis of staging of since its introduction in the early 1990s. [13] When compared to other procedures such as mediastinoscopy, conventional TBNA, and transesophageal endoscopic ultrasound-guided fine-needle aspiration (EUS-FNA), EBUS has been shown to improve the diagnostic yield for sampling mediastinal and hilar lymph nodes in multiple studies [1416]. Notably, the addition of mediastinoscopy to EBUS has not been shown to be better than EBUS alone, however the two technologies have been shown to be complementary to each other [16,17].

EBUS-TBNA is an outpatient procedure that can be done safely using moderate sedation; the use of general anesthesia may improve diagnostic yield [18]. To obtain tissue specimens for cytology, a convex probe endobronchial ultrasound bronchoscope is introduced into the airway. The mediastinum and hilum are then systematically scanned with the ultrasound probe following standard lung cancer staging guidelines [19]. Once identified, the lymph node is sampled with a 19-, 21- or 22-gauge needle using real-time visualization via ultrasound image. A stylet is often left in place during puncture of the airway wall into the desired lymph node to minimize sample contamination. The stylet is then briskly agitated in an up and down motion to remove debris and expel additional bronchial wall contamination of the TBNA sample. A recent study suggests that the stylet may be unnecessary given that its absence did not reduce diagnostic yield [20]. Suction may be applied while sampling the target lymph node with the needle. Suction does not increase diagnostic yield, but has been shown to improve cellularity. Its use can be a disadvantage due to the potential to increase blood contamination of the sample [21]. Multiple passes are performed while the needle is within the lymph node. If suction is utilized, it should be removed prior to retraction of the needle to avoid contamination or loss of sample. The specimen can then be given to a cytopathologist/technologist for rapid on-site evaluation (ROSE) or prepared by the bronchoscopy team for subsequent analysis.

Despite studies showing EBUS-TBNA equivalence and even potential superiority to more invasive surgical techniques, questions remained until recently as to whether EBUS-TBNA sampling was a sufficient means of tissue acquisition for molecular analysis. Multiple publications have since shown EBUS-TBNA to be more than adequate in acquisition of tissue for molecular analysis [22-28]. Billah, et al. analyzed 99 NSCLC positive EBUS TBNA samples for EGFR and KRAS molecular testing. Samples were considered appropriate for molecular analysis when at least forty percent of tissue samples contained tumor cells. Only four of the 99 samples (4\%) were deemed insufficient for EGRF or KRAS molecular testing [26]. Nakajima, et al. performed EGFR analysis on tissue samples from 156 patients with NSCLC. EGFR gene status was determined in 154 of the 156 patients (98.7\%) [28]. Finally, a recent study by Sakarakibara, et al. evaluated PD-L1 expression in six EBUS TBNA lymph node samples from NSCLC patients and the corresponding primary tumor. There was a positive correlation between these samples with a correlation coefficient of 0.75 [29].

Molecular analysis requires a sufficient number and concentration of tumor cells. The number of cells needed for molecular testing depends on the mutation being tested, with Epidermal Growth Factor Receptor (EGFR) requiring a minimum of 500 tumor cells and KRAS requiring 200 [30-32]. It is generally accepted that three passes per lymph node station is sufficient for optimal diagnostic yield with EBUS-TBNA [33]. The number of needle passes needed required to provide adequate tissue for molecular analysis remains unknown. Indirectly, this number has been estimated using data demonstrating that three passes was sufficient for molecular analysis in over $95 \%$ of patients [26-28,34].

The utility of ROSE in the yield of EBUS-TBNA remains a controversial topic. Two prospective randomized trials failed to show a diagnostic benefit with the use of ROSE during conventional TBNA, but did show a decrease in procedure related complications due to a decreased need to sample the parenchymal lesion [35,36]. For EBUSTBNA, a recent retrospective study demonstrated that the use of ROSE did improve diagnostic yield [37]. In evaluating EBUS-TBNA, ROSE has been shown to help provide accurate and sensitive methodologies for the diagnosis and staging of lung cancer [38]. There is a paucity of data on the effect of ROSE on tissue acquisition using EBUS-TBNA for molecular analysis.

Finally, the question of needle size and diagnostic yield has also been evaluated with a recent large multi-centered retrospective study finding no significant difference in diagnostic yield between the 21 and 22 gauge needles for EBUS [39]. While the current literature does not provide evidence of difference in diagnostic yield between available EBUS-TBNA needle sizes, a recent retrospective study did note superior cellular quality of specimens harvested using the 21-gauge needle [40].

\section{Electromagnetic Navigational Bronchoscopy (ENB)}

Following adequate mediastinal LN sampling and staging, ENB can be utilized to sample a peripheral nodule or mass. As with EBUSTBNA, ENB has been shown to provide sufficient tissue sample for molecular analysis $[41,42]$.

ENB requires dedicated thin-section, high resolution computed tomography (CT) scans to create a three-dimensional airway map. Depending on the manufacturer, an electromagnetic field is either placed above or below the supine patient. This field, in conjunction with the manufacturer specific tools, allows for real-time, virtual guidance of the bronchoscope through the patient's airways. After navigating to the target, biopsies of the lesions can be using several different instrument techniques (forceps biopsies, fine needle aspirates, brushes, etc.). ENB can be performed using moderate to deep sedation 
with similar diagnostic yield [43].

A recent meta-analysis reported that ENB performance with regards to diagnostic accuracy is approximately $74 \%$. ENB had a pneumothorax rate of $3.1 \%$, with approximately half of those patients requiring chest tube placement. Additionally, $0.9 \%$ of patients experienced minor to moderate bleeding, with no severe bleeding noted [44].

\section{Transthoracic approaches}

Peripheral nodules or masses not adjacent to an airway may be difficult to access using a bronchoscopic approach. CT-guided transthoracic needle aspiration (CT-TNA) and electromagnetic navigational transthoracic needle aspiration (EMTTNA) approaches are two techniques available to assist in peripheral tissue acquisition.

\section{CT-Guided lung biopsy}

CT-guided lung biopsy is an outpatient procedure that is performed using light conscious sedation and local anesthesia. The procedure begins with the patient positioned on the CT gantry such that the lung lesion is most easily accessed by the radiologist. Using CT-guidance, the lesion is identified and a large bore needle is inserted through the skin into the thoracic cavity using sterile technique. Biopsy of the lesion in question is then performed using a core biopsy needle, fine needle aspirate or both and sent for pathologic evaluation [45].

The diagnostic yield of CT guided lung biopsy is approximately 95\% [46-48]. Compared to bronchoscopic techniques, the risk of pneumothorax and subsequent chest tube placement is much higher, at $15-28 \%$ and $2.5-6.6 \%$ respectively [49-52]. Additionally, this approach is not ideal if the patient needs complete lung cancer staging of the hilum and mediastinum. As for molecular testing, image-guided lung biopsies have been shown to have a higher tumor genotyping failure rate of $32 \%$ compared to transbronchial approaches with a failure rate of $11 \%[53]$.

\section{Electromagnetic Navigation Transthoracic Needle Aspiration (EMTTNA)}

EMTTNA is an emerging technique for peripheral lung nodule biopsy [54]. Should the lesion not be accessible via bronchoscopy, a manufacturer-specific needle with an electromagnetic tip is then advanced from the chest wall into the thoracic cavity to the desired location using the virtual image generated by the ENB software as a guide. Biopsy of the lesion is then performed in same manner as CTguided biopsy.

Limited data exists regarding its safety and efficacy. Early data indicates a diagnostic yield of $82 \%$ with EMTTNA alone, and $87 \%$ when combining EMTTNA with ENB. The advantage of EMTTNA over CT guided lung biopsy is that it can be performed during the same procedure as EBUS and ENB, which allows for full staging of the mediastinum and hilum with minimal increase in anesthetic time. As for complications, pneumothorax and subsequent chest tube placement rates seem to be comparable to CT guided lung biopsy. Twenty-four percent of patients undergoing EMTTNA had a pneumothorax with $8 \%$ requiring a chest tube $[54,55]$.

\section{Specimen preparation}

Fine needle aspiration preparation is essentially the same regardless of the method through which the biopsy is obtained. FNA material is extruded through the needle and a small amount of material is placed on a glass slide. This is followed by either repeatedly flushing the needle into saline or an alcohol based preservative for later centrifugation and/ or creation of a cell block using the tissue coagulum clot method (TCCCB) $[56,57]$. It is important to note that if lymphoma is suspected, the material should not be placed in alcohol as flow cytometry will not be able to be performed. The slides may be further processed by either an air-drying method or a wet-prep method. Air-dried slides are stained using the Diff-Quik method while wet-fixed slides are immersed in 95\% alcohol and stained by Papanicolaou method in a cytology laboratory.

When ROSE is employed an immediate assessment is given to the bronchoscopist after each needle puncture into the lymph node. If on-site evaluation reveals diagnostic material, the remaining material from additional aspirations is processed for cell block. Once diagnostic material is seen, additional passes are performed, processed and reviewed until the cytotechnologist reports that the material present in the coagulum contains an estimated tumor burden of over $25 \%[31,58]$. If the evaluation does not reveal tumor, a minimum of three needle passes into the lymph node at each station is recommended [33].

Preparation of the TCC-CB is performed by gently extruding the material within the cytology needle using the wire stylet onto a precut filter paper with the needle tip rotated in a tight circular motion to build up a coagulum of tissue and blood mixture [57]. The TCC-CB is then fixed in formalin and processed in a histology laboratory to prepare the cell block. Paraffin sections of tumor in 4-5 micron sections are then mounted on glass slides and reviewed by a pathologist to confirm a diagnosis of NSCLC, once confirmed the specimens can be sent for molecular testing.

\section{Mutation and gene fusion analysis}

It is currently recommended that all lung adenocarcinomas be tested for EGFR and ALK mutations, regardless of age, gender or ethnicity, given the emergence of targeted therapy against these driver mutations [2,59]. Several large studies have shown this to be an achievable expectation $[60,61]$. Over the course of one year, Barlesi, et al. evaluated the time from initiation of molecular analysis to final report in 18, 679 samples from 17,664 patients. They found the mean time to be 11 days, and demonstrated that $51 \%$ of those with a targetable mutation had their treatment course altered due to the result [60]. Kris, et al. demonstrated that routine testing of actionable mutations, which included EGFR and KRAS, was achievable, with 733 patients tested in a three-year period. This study also suggested a survival benefit in those with actionable mutations who were given targeted therapy versus those not given targeted therapy [61]. Concurrent testing for KRAS mutations is also recommended, given that a positive result portends a worse prognosis and resistance to EGFR specific therapies $[62,63]$. Extended panels of gene mutations can be performed to include such potential targets as ROS-1, BRAF, HER2, MET and MEK1. The recommended turn-around time from sampling to molecular results is 5-10 working days. Most importantly, current recommendations strongly advise that a multidisciplinary team define appropriate patient criteria for molecular testing at the institutional level [59].

Next-generation sequencing (NGS), which is also known as "high-throughput sequencing", has allowed for more efficient and cost-effective detection of these targetable lung cancer mutations [64]. Compared to standard Sanger sequencing or PCR, NGS sequences multiple DNA fragments in parallel, which offers more comprehensive data of the desired gene with comparable accuracy [65]. With respect to tissue acquisition for NGS in NSCLC, FNA samples have been shown to be equal to formalin fixed paraffin-embedded (FFPE) samples [66]. 


\section{EGFR}

EGFR is a membrane bound tyrosine kinase which is an upstream modulator of a complex array of cell proliferation signals [67]. The specific EGFR mutations driving much of the sensitivity to tyrosine kinase inhibition (TKI) were first identified in 2004 following a subgroup analysis of patients who showed tumor responsiveness during treatment with a TKI [30,31]. The EGFR mutation is most common in non-smoking Asian females with adenocarcinoma, though it is frequently found outside of this demographic $[31,68,69]$. While the EGFR mutation has also been found in other types of NSCLC, it is most frequently associated with adenocarcinoma [70].

There are currently 3 EGFR-targeted TKIs: gefitinib, erlotinib and afatinib. Numerous randomized controlled trials have been conducted using these drugs as first line, second line, and maintenance agents. In 2009, a seminal study randomizing never or light smoking patients with newly diagnosed stage IIIB or IV lung adenocarcinoma to receive either gefitinib or carboplatin and paclitaxel was performed. Patients receiving gefitinib had superior progression free survival compared to patients receiving carboplatin and paxlitaxel of $24.9 \%$ and $6.7 \%$, respectively. Patients with the EGFR mutation had an even more dramatic response while those without the mutation had better progression free survival with standard carboplatin and paclitaxel treatment [71]. Another early EGFR TKI trial randomized patients with EGFR mutation positive stage IIIb or IV adenocarcinoma to treatment with afatinib - an irreversible oral EGFR TKI - or gemcitabine and cisplatin. Treatment with afatinib prolonged progression free survival to 11.0 months as opposed to 5.6 months with gemcitabine and cisplatin [72]. Several meta-analyses have been conducted thus far on the overall effect of EFGR TKIs vs. conventional cytotoxic chemotherapy including up to 13 individual trials. The aggregate data indicates that EGFR-targeted drugs improve progression free survival but have no impact on overall mortality $[73,74]$.

Once a patient with an EGFR mutation containing NSCLC is initiated on EGFR-targeted therapy, they often acquire resistance to the inhibitor, often within a year of starting treatment [75]. In up to half of patients who develop resistance, the mutation T790M has been found. This involves a substitution of methionine for threonine at position 790 [76]. Third generation TKIs developed to target the T790M mutation are emerging as therapeutic treatments $[75,77,78]$. Recently, the third generation TKI osimertinib was approved by the FDA for patients with metastatic, T790M mutation positive NSCLC. This irreversible oral agent has activity for both EGFR and T790M mutations [79]. In the phase III trial of osimertinib vs platinum based therapy plus pemetrexed, 419 patients with advanced T790M positive NCSCL that had progressed while on first generation TKI therapy were selected. These patients were randomly assigned to osimertinib or either cisplatin or carboplatin with pemetrexed with progression free survival as the primary endpoint. Progression free survival in the osimertinib group was 8.5 months, compared to the platinum-based therapy group at 4.2 months. Furthermore, the frequency of severe side effects was lower in the osimertinib group (23\%) compared to the platinum-based therapy (47\%) [80].

\section{ELM4-ALK}

The ALK fusion gene was first detected in NSCLC in 2007. The fusion gene involves a rearrangement of the echinoderm microtubuleassociated protein-like 4 (EML4) gene and the anaplastic lymphoma kinase (ALK) [81]. The ELM4-ALK fusion gene is the dominant ALK- gene rearrangement in adenocarcinoma but others have been described [82].

Patients with the ALK fusion gene have unique clinical characteristics; they are overall younger and more likely to be light or never smokers [83-85]. At least one study suggests that the rearrangement may be more common in men [84]. The fusion gene is found in approximately $3.8 \%$ of NSCLCs, a vast majority of which are adenocarcinomas [85]. Tumor histology appears to offer little predictive value for ALK positivity as there a wide variation in of histological subtypes among positive tumors $[83,86]$.

ALK positivity has significant therapeutic implications as patients with the chromosomal rearrangement show response to the TKI, Crizotinib. Crizotinib acts via inhibition of the c-Met/Hepatocyte growth factor receptor (HGFR) tyrosine kinase by competitively binding to the tyrosine kinase ATP binding pocket. One phase III has been conducted to evaluate the efficacy of crizotinib. ALK-positive patients with locally advanced or metastatic who had received at least one platinum-based therapy were randomized to treatment with crizotinib or conventional therapy with either pemetrexed or docetaxel. Treatment with crizotinib increased progression free survival to 7.7 months vs. 3.0 months with conventional chemotherapy [87].

Just as with EGFR, most patients who are treated with a first generation ALK inhibitor eventually acquire resistance to the drug, usually within the first 10-12 months of treatment [88]. However, unlike EGFR, the mutations for ALK inhibitor resistance are much more heterogeneous [89]. Approximately 30 percent of acquired mutations is the L1196M mutation, which replaces leucine for methionine at position 1196. This, along with other mutations such as G1269A and S1206Y, affects the ATP-binding domain [88,90]. Additional mutations include ALK amplification, which allows the tumor cell to continue downstream signally despite presence of an ALK inhibitor [88]. Ceritinib is a second-generation ALK inhibitor, which is FDA approved for those ALK-positive NSCLC patients with metastatic disease who have had disease progression while on crizotinib. The phase II ASCEND-2 trial evaluated the efficacy of ceritinib in this patient population. A total of 140 patients who had all been previously treated with crizotinib were treated with ceritinib. Overall response rate to the drug was $38.6 \%$, with a duration of response averaging 9.7 months. Serious drug-related adverse events occurred in approximately $17 \%$ of patients [91].

Recently, data from the phase III ASCEND-4 trial suggests that ceritinib improves progression free survival as first line therapy compared to platinum based therapy in patients with advanced NSCLC who harbor an ALK mutation. This randomized trial evaluated a total of 376 patients, and found that progression free survival averaged 16.6 months in the ceritinib group compared to 8.1 months in the chemotherapy group. Additionally, the side effect profile for ceritinib was favorable compared to the platinum based therapy group [92].

\section{KRAS}

The RAS family of oncogenes were first discovered in the 1960's through the study of oncoviruses [93]. KRAS, a subtype of RAS, was first discovered in NSCLC in 1984 and was later found to play a significant upstream role in cell proliferation signaling [94,95]. Traditionally, all KRAS mutations were thought to be associated with smoking, however a recent study failed to uphold this relationship, instead a specific type of KRAS mutation was identified that may be influenced by patient smoking status $[96,97]$. KRAS mutations are more common in western Europeans than in African Americans and Asians $[98,99]$. 
In contrast to EGFR, targeted therapies against KRAS-mutation positive NSLCL have not been effective. However, recently there have been some Phase II trials that have shown promise against downstream targets of the KRAS signaling pathway. One such study randomized patients with advanced stage NSCLC to selumetinib with docetaxel or placebo with docetaxel. Selumetinib is a selective inhibitor of the MEK1/MEK2 kinases, which is part of the MAPK signaling pathway. The selumetinib group had statistically significant improvement in median survival and progression free survival compared to the placebo group (9.4 months versus 5.2 months and 5.3 versus 2.1 months, respectively). However, the selumetinib group did experience significantly more adverse events [100].

Testing for KRAS is frequently conducted as KRAS mutations occur exclusively of ALK and EGFR and for the potential prognostic value of KRAS positivity [62]. The presence of KRAS indicates that a patient will likely be resistant to EGFR specific tyrosine kinase inhibitors [63]. Traditionally, KRAS positivity has been considered to portend a poor overall prognosis. A recent meta-analysis which included 28 distinct data sets found that the presence of the KRAS mutation was associated with a hazard ratio of 1.35 . While this is consistent with an overall increase risk of morbidity and mortality in the presence of the KRAS mutation, the effect appears small [101].

\section{Check point inhibition}

\section{PD-1/PD-L1}

Recently, the importance of immune checkpoint molecules has emerged [102-106]. In particular, programmed death 1 (PD-1) and programmed death ligand 1 (PD-L1) have monoclonal antibodies directed towards them, which have shown promise with regards to overall survival in advanced NSCLC. These drugs bind to the inhibitory checkpoint molecules, blocking their ability to inactivate specific immune cells [107]. Currently, there are two FDA-approved monoclonal antibodies to PD-1, nivolumab and pembrolizumab. Both of these therapies have shown promise in patients with previously treated advanced NSCLC [108], with improvement in overall survival compared to platinum-based chemotherapy. Of note, there appears to be a clinical benefit regardless of PD-L1 expression in nivolumab therapy, while PD-L1 expression status is much more important in predicting response to pembrolizumab $[4,102,104]$.

The CheckMate 057 trial was a phase III trial that evaluated nivolumab versus docetaxel in non-squamous NSCLC patients who had progressed after first-line chemotherapy. This study showed an overall survival of 9.2 months in the nivolumab arm compared to 0.9 months in the docetaxel arm in patients with previously treated non-squamous NSCLC. Additionally, the nivolumab group had a treatment-related adverse event rate of $10 \%$, compared to $54 \%$ rate in the docetaxel arm [103]. Likewise, KEYNOTE-010 was a phase II/III trial which evaluated overall survival and progression free survival in previously treated, advanced NSCLC patients receiving pembrolizumab versus docetaxel. Patients had to have tumors with at least 50\% PD-L1 expression. This study demonstrated an overall survival advantage of 14.9 and 17.3 months versus 8.2 months in the pembrolizumab groups, which were stratified based on drug dosing, compared to docetaxel in previously treated PD-L1 positive NSCLC, respectively. As with nivolumab, pembrolizumab had a better safety profile compared to docetaxel, regardless of dose [104].

Recently, Reck, et al. evaluated the efficacy of pembrolizumab versus platinum-based chemotherapy in treatment naïve PD-L1 positive NSCLC patients in a phase III trial. Patients with actionable mutations such as EGFR or ALK were excluded. The pembrolizumab group had a response rate of $44.8 \%$ compared to the platinum-based group response rate of $27.8 \%$. Furthermore, the pembrolizumab group had a median progression-free survival duration of 10.3 months, compared to 6 months in the chemotherapy group. Again, serious adverse reactions were less in the immunotherapy group [105]. In the phase II KEYNOTE-21 study, treatment naïve advanced stage NSCLC patients without actionable mutations were treated with firstline chemotherapy either alone or combined with pembrolizumab. One-hundred twenty-three patients were randomly assigned to either treatment group, and the primary endpoint was objective response rate. The pembrolizumab demonstrated a better objective response rate of $55 \%$, compared to $29 \%$ in the other group. Progression free survival was 13 vs 6 months in the combined group compared to the chemotherapy only group, respectively. The pembrolizumab group did have a slightly higher incidence of grade 3 or higher adverse events when compared to the chemotherapy alone group, $39 \%$ versus $26 \%$, respectively [106].

\section{Conclusion}

The analysis of genetic mutations and chromosomal rearrangement has the potential to significantly impact both the treatment and prognosis of patients diagnosed with NSCLC. This makes the procurement of tissue of utmost importance. Given that many of these patients are diagnosed in the advanced stages of cancer, it behooves us to acquire this information in the least invasive manner. Flexible bronchoscopy and EBUS-TBNA have clearly placed themselves as the first line options for tissue acquisition from the lung parenchyma and well as hilum and mediastinum. In the event that EBUS-TBNA is unavailable or unable to access the lymph nodes or lesion then more invasive radiologic or surgical means should be undertaken.

\section{References}

1. Siegel RL, Miller KD, Jemal A (2016) Cancer statistics, 2016. CA Cancer J Clin 66:730 .

2. Kerr KM, Bubendorf L, Edelman MJ, Marchetti A, Mok T, et al. (2014) Second ESMO consensus conference on lung cancer: pathology and molecular biomarkers for nonsmall-cell lung cancer. Ann Oncol 25: 1681-1690.[Crossref]

3. Rekhtman N, Leighl NB, Somerfield MR (2015) Molecular testing for selection of patients with lung cancer for epidermal growth factor receptor and anaplastic lymphoma kinase tyrosine kinase inhibitors: American society of clinical oncology endorsement of the college of American pathologists/international association for the study of lung cancer/association for molecular pathology guideline. J Oncol Pract 11: 135-136.

4. Hirsch FR, Suda K, Wiens J, Bunn PA Jr (2016) New and emerging targeted treatments in advanced non-small-cell lung cancer. Lancet 388: 1012-1024.[Crossref]

5. Chee J, Robinson BW, Holt RA, Creaney J (2016) Immunotherapy of lung malignancies - from gene sequencing to novel therapies. Chest S0012-3692: 60776[Crossref]

6. Travis WD, Brambilla E, Noguchi M, Nicholson AG, Geisinger KR, et al. (2011) International association for the study of lung cancer/american thoracic society/ european respiratory society international multidisciplinary classification of lung adenocarcinoma. J Thorac Oncol 6:244-285.

7. Silvestri GA, Gould MK, Margolis ML, Tanoue LT, McCrory D, (2007)Noninvasive staging of non-small cell lung cancer: ACCP evidenced-based clinical practice guidelines (2nd edition). Chest 132:178S-201S.

8. Detterbeck FC, Jantz MA, Wallace M, Vansteenkiste J, Silvestri GA (2007) Invasive mediastinal staging of lung cancer: ACCP evidence-based clinical practice guidelines (2nd edition). Chest 132:202S-220S.

9. Erasmus JJ, Sabloff BS (2008) CT, positron emission tomography, and MRI in staging lung cancer. Clin Chest Med 29: 39-57. [Crossref]

10. Medford AR, Bennett JA, Free CM, Agrawal S (2009) Mediastinal staging procedures 
in lung cancer: EBUS, TBNA and mediastinoscopy. Curr Opin Pulm Med 15: 334-342. [Crossref]

11. Toloza EM, Harpole L, Detterbeck F, McCrory DC (2003) Invasive staging of nonsmall cell lung cancer: a review of the current evidence. Chest 123: 157S-166S. [Crossref]

12. De Leyn P, Stroobants S, De Wever W, Lerut T, Coosemans W, et al. (2006) Prospective comparative study of integrated positron emission tomography-computed tomography scan compared with remediastinoscopy in the assessment of residual mediastinal lymph node disease after induction chemotherapy for mediastinoscopyproven stage IIIA-N2 Non-small-cell lung cancer: a Leuven Lung Cancer Group Study. J Clin Oncol 24:3333-3339.

13. Eapen GA, Shah AM, Lei X, Jimenez CA, Morice RC, et al. (2013) Complications, consequences, and practice patterns of endobronchial ultrasound-guided transbronchial needle aspiration: Results of the AQuIRE registry. Chest 143:1044-1053.

14. Herth FJ (2011) Nonsurgical staging of the mediastinum: EBUS and EUS. Semin Respir Crit Care Med 32: 62-68.[Crossref]

15. Silvestri GA, Gonzalez AV, Jantz MA, Margolis ML, Gould MK,et al. (2013) Methods for staging non-small cell lung cancer: Diagnosis and management of lung cancer, 3rd ed: American College of Chest Physicians evidence-based clinical practice guidelines. Chest 143: e211S-50S.

16. Yasufuku K, Pierre A, Darling G, de Perrot M, Waddell T, et al. (2011) A prospective controlled trial of endobronchial ultrasound-guided transbronchial needle aspiration compared with mediastinoscopy for mediastinal lymph node staging of lung cancer. $J$ Thorac Cardiovasc Surg 142:1393-400.e1.

17. Ernst A, Anantham D, Eberhardt R, Krasnik M, Herth FJ (2008) Diagnosis of mediastinal adenopathy-real-time endobronchial ultrasound guided needle aspiration versus mediastinoscopy. J Thorac Oncol 3: 577-582.

18. Yarmus LB, Akulian JA, Gilbert C, Mathai SC, Sathiyamoorthy S, et al. (2013) Comparison of moderate versus deep sedation for endobronchial ultrasound transbronchial needle aspiration. Ann Am Thorac Soc 10: 121-126.

19. Gilbert C, Yarmus L, Feller-Kopman D (2012) Use of endobronchial ultrasound and endoscopic ultrasound to stage the mediastinum in early-stage lung cancer. $J$ Natl Compr Canc Netw 10: 1277-1282.[Crossref]

20. Scholten EL, Semaan R, Illei P, Mallow C, Arias S, et al. (2016) Stylet Usage Does Not Improve Diagnostic Outcomes in Endobronchial Ultrasound Transbronchial Needle Aspiration: A Randomized Clinical Trial. Chest 151: 3.

21. Casal RF, Staerkel GA, Ost D, Almeida FA, Uzbeck MH, et al. (2012) Randomized clinical trial of endobronchial ultrasound needle biopsy with and without aspiration. Chest 142: 568-573.[Crossref]

22. Van Eijk R, Licht J, Schrumpf M, Talebian Yazdi M, Ruano D, et al. (2011) Rapid KRAS, EGFR, BRAF and PIK3CA mutation analysis of fine needle aspirates from non-small-cell lung cancer using allele-specific qPCR. PLoS One 6:e17791.

23. Sakairi Y, Nakajima T, Yasufuku K, Ikebe D, Kageyama H, et al. (2010) EML4ALK fusion gene assessment using metastatic lymph node samples obtained by endobronchial ultrasound-guided transbronchial needle aspiration. Clin Cancer Res 16: 4938-4945.

24. Schuurbiers OC, Looijen-Salamon MG, Ligtenberg MJ, van der Heijden HF (2010) A brief retrospective report on the feasibility of epidermal growth factor receptor and KRAS mutation analysis in transesophageal ultrasound- and endobronchial ultrasoundguided fine needle cytological aspirates. J Thorac Oncol 5:1664-1667.

25. Nakajima T, Yasufuku K, Suzuki M, Hiroshima K, Kubo R, et al. (2007) Assessment of epidermal growth factor receptor mutation by endobronchial ultrasound-guided transbronchial needle aspiration. Chest 132: 597-602.[Crossref]

26. Billah S, Stewart J, Staerkel G, Chen S, Gong Y, et al. (2011) EGFR and KRAS mutations in lung carcinoma: molecular testing by using cytology specimens. Cancer Cytopathol 119:111-117.

27. Tanner NT, Watson P, Boylan A, Memoli JS, Pastis N, et al. (2011) Utilizing endobronchial ultrasound with fine-needle aspiration to obtain tissue for molecular analysis: a single-center experience. J Bronchology Interv Pulmonol 18: 317-321.

28. Nakajima T, Yasufuku K, Nakagawara A, Kimura H, Yoshino I (2011) Multigene mutation analysis of metastatic lymph nodes in non-small cell lung cancer diagnosed by endobronchial ultrasound-guided transbronchial needle aspiration. Chest 140: 13191324.

29. Sakakibara R, Inamura K, Tambo Y, Ninomiya H, Kitazono S, et al. (2016) EBUSTBNA as a Promising Method for the Evaluation of Tumor PD-L1 Expression in Lung
Cancer. Clin Lung Cancer. [Crossref]

30. Lynch TJ, Bell DW, Sordella R, Gurubhagavatula S, Okimoto RA, et al. (2004) Activating mutations in the epidermal growth factor receptor underlying responsiveness of non-small-cell lung cancer to gefitinib. N Engl J Med 350:2129-2139.

31. Pao W, Miller V, Zakowski M, Doherty J, Politi K, et al. (2004) EGF receptor gene mutations are common in lung cancers from "never smokers" and are associated with sensitivity of tumors to gefitinib and erlotinib. Proc Natl Acad Sci U S A 101: 1330613311.[Crossref]

32. Paez JG, Janne PA, Lee JC, Tracy S, Greulich H, et al. (2004)EGFR mutations in lung cancer: correlation with clinical response to gefitinib therapy. Science 304:1497-1500.

33. Lee HS, Lee GK, Lee HS, Kim MS, Lee JM, et al. (2008) Real-time endobronchial ultrasound-guided transbronchial needle aspiration in mediastinal staging of non-small cell lung cancer: how many aspirations per target lymph node station? Chest 134: 368374 .

34. Navani N, Brown JM, Nankivell M, Woolhouse I, Harrison RN, et al. (2012) Suitability of endobronchial ultrasound-guided transbronchial needle aspiration specimens for subtyping and genotyping of non-small cell lung cancer: a multicenter study of 774 patients. Am J Respir Crit Care Med 185: 1316-1322.

35. Trisolini R, Cancellieri A, Tinelli C, Paioli D, Scudeller L, et al. (2011) Rapid onsite evaluation of transbronchial aspirates in the diagnosis of hilar and mediastinal adenopathy: a randomized trial. Chest 139:395-401.

36. Yarmus L, Van der Kloot T, Lechtzin N, Napier M, Dressel D, et al. (2011) A randomized prospective trial of the utility of rapid on-site evaluation of transbronchial needle aspirate specimens. J Bronchology Interv Pulmonol 18:121-127.

37. Guo H, Liu S, Guo J, Li B, Li W, et al. (2016) Rapid on-site evaluation during endobronchial ultrasound-guided transbronchial needle aspiration for the diagnosis of hilar and mediastinal lymphadenopathy in patients with lung cancer. Cancer Lett 371: 182-186.

38. Feller-Kopman D, Yung RC, Burroughs F, Li QK (2009) Cytology of endobronchial ultrasound-guided transbronchial needle aspiration: a retrospective study with histology correlation. Cancer 117(6):482-490.

39. Yarmus LB, Akulian J, Lechtzin N, Yasin F, Kamdar B, et al. (2013) Comparison of 21-gauge and 22-gauge aspiration needle in endobronchial ultrasound-guided transbronchial needle aspiration: results of the American College of Chest Physicians Quality Improvement Registry, Education, and Evaluation Registry. Chest 143: 10361043.

40. Nakajima T, Yasufuku K, Takahashi R, Shingyoji M, Hirata T, et al. (2011) Comparison of 21-gauge and 22-gauge aspiration needle during endobronchial ultrasound-guided transbronchial needle aspiration. Respirology 16: 90-94.

41. Anderson JC, Minnich DJ, Dobelbower MC, Denton AJ, Dussaq AM, et al. (2014) Kinomic profiling of electromagnetic navigational bronchoscopy specimens: a new approach for personalized medicine. PLoS One 9: e116388.

42. Ha D, Choi H, Almeida FA, Arrossi A, Brainard J, et al. (2013) Histologic and molecular characterization of lung cancer with tissue obtained by electromagnetic navigation bronchoscopy. J Bronchology Interv Pulmonol 20:10-15.

43. Bowling MR, Kohan MW, Walker P, Efird J, Ben S (2015) The effect of general anesthesia versus intravenous sedation on diagnostic yield and success in electromagnetic navigation bronchoscopy. J Bronchology Interv Pulmonol 22:5-13.

44. Gex G, Pralong JA, Combescure C, Seijo L, Rochat T, et al. (2014) Diagnostic yield and safety of electromagnetic navigation bronchoscopy for lung nodules: a systematic review and meta-analysis. Respiration 87:165-176.

45. Birchard KR (2011) Transthoracic needle biopsy. Semin Intervent Radiol 28: 87-97. [Crossref]

46. Hiraki T, Mimura H, Gobara H, Iguchi T, Fujiwara H, et al. (2009) CT fluoroscopyguided biopsy of 1,000 pulmonary lesions performed with 20-gauge coaxial cutting needles: diagnostic yield and risk factors for diagnostic failure. Chest 136: 1612-1617.

47. Lee SM, Park CM, Lee KH, Bahn YE, Kim JI, et al. (2014) C-arm cone-beam CTguided percutaneous transthoracic needle biopsy of lung nodules: clinical experience in 1108 patients. Radiology 271: 291-300.

48. Wang Y, Jiang F, Tan X, Tian P (2016) CT-guided percutaneous transthoracic needle biopsy for paramediastinal and nonparamediastinal lung lesions: Diagnostic yield and complications in 1484 patients. Medicine 95: e4460.

49. Narula T, Machuzak MS, Mehta AC (2013) Newer modalities in the work-up of peripheral pulmonary nodules. Clin Chest Med 34: 395-415.[Crossref] 
50. Wiener RS, Schwartz LM, Woloshin S, Welch HG (2011) Population-based risk for complications after transthoracic needle lung biopsy of a pulmonary nodule: an analysis of discharge records. Ann Intern Med 155: 137-144.

51. Geraghty PR, Kee ST, McFarlane G, Razavi MK, Sze DY, et al. (2003) CT-guided transthoracic needle aspiration biopsy of pulmonary nodules: needle size and pneumothorax rate. Radiology 229: 475-481.[Crossref]

52. Ohno Y, Hatabu H, Takenaka D, Higashino T, Watanabe H, et al.(2003) CT-guided transthoracic needle aspiration biopsy of small $(<$ or $=20 \mathrm{~mm})$ solitary pulmonary nodules. AJR Am J Roentgenol 180:1665-1669.

53. Vanderlaan PA, Yamaguchi N, Folch E, Boucher DH, Kent MS, et al. (2014) Success and failure rates of tumor genotyping techniques in routine pathological samples with non-small-cell lung cancer. Lung Cancer 84: 39-44.

54. Yarmus LB, Arias S, Feller-Kopman D, Semaan R, Wang KP, et al. (2016) Electromagnetic navigation transthoracic needle aspiration for the diagnosis of pulmonary nodules: a safety and feasibility pilot study. J Thorac Dis 8:186-194.

55. Arias S, Yarmus L, Argento AC (2015) Navigational transbronchial needle aspiration, percutaneous needle aspiration and its future. J Thorac Dis7: S317-28.

56. Yasufuku K, Chiyo M, Sekine Y, Chhajed PN, Shibuya K, et al.(2004) Real-time endobronchial ultrasound-guided transbronchial needle aspiration of mediastinal and hilar lymph nodes. Chest 126:122-128.

57. Yung RC, Otell S, Illei P, Clark DP, Feller-Kopman D, et al. (2012) Improvement of cellularity on cell block preparations using the so-called tissue coagulum clot method during endobronchial ultrasound-guided transbronchial fine-needle aspiration. Cancer Cytopathol 120:185-195.

58. Yu HA, Arcila ME, Rekhtman N, Sima CS, Zakowski MF, et al. (2013) Analysis of tumor specimens at the time of acquired resistance to EGFR-TKI therapy in 155 patients with EGFR-mutant lung cancers. Clin Cancer Res 19: 2240-2247.

59. Lindeman NI, Cagle PT, Beasley MB, Chitale DA, Dacic S, et al. (2013) Molecular testing guideline for selection of lung cancer patients for EGFR and ALK tyrosine kinase inhibitors: guideline from the College of American Pathologists, International Association for the Study of Lung Cancer, and Association for Molecular Pathology. $J$ Thorac Oncol 8: 823-859.

60. Barlesi F, Mazieres J, Merlio JP, Debieuvre D, Mosser J, et al. (2016) Routine molecular profiling of patients with advanced non-small-cell lung cancer: results of a 1-year nationwide programme of the French Cooperative Thoracic Intergroup (IFCT). Lancet 387: 1415-1426.

61. Kris MG, Johnson BE, Berry LD, Kwiatkowski DJ, Iafrate AJ, et al. (2014) Using multiplexed assays of oncogenic drivers in lung cancers to select targeted drugs. JAMA 311: $1998-2006$

62. Gainor JF, Varghese AM, Ou SH, Kabraji S, Awad MM, et al. (2013) ALK rearrangements are mutually exclusive with mutations in EGFR or KRAS: an analysis of 1,683 patients with non-small cell lung cancer. Clin Cancer Res 19: 4273-4281. [Crossref]

63. Mao C, Qiu LX, Liao RY, Du FB, Ding H, et al. (2010) KRAS mutations and resistance to EGFR-TKIs treatment in patients with non-small cell lung cancer: a meta-analysis of 22 studies. Lung Cancer 69: 272-278.[Crossref]

64. Kruglyak KM, Lin E, Ong FS (2016) Next-Generation Sequencing and Applications to the Diagnosis and Treatment of Lung Cancer. Adv Exp Med Biol 890: 123-136. [Crossref]

65. Strom SP, Lee H, Das K, Vilain E, Nelson SF, et al. (2014) Assessing the necessity of confirmatory testing for exome-sequencing results in a clinical molecular diagnostic laboratory. Genet Med 16: 510-515.

66. Karnes HE, Duncavage EJ, Bernadt CT (2014) Targeted next-generation sequencing using fine-needle aspirates from adenocarcinomas of the lung. Cancer Cytopathol 122: 104-113.[Crossref]

67. Normanno N, De Luca A, Bianco C, Strizzi L, Mancino M, et al. (2006) Epidermal growth factor receptor (EGFR) signaling in cancer. Gene 366: 2-16.[Crossref]

68. Kawaguchi T, Koh Y, Ando M, Ito N, Takeo S, et al. (2016)Prospective Analysis of Oncogenic Driver Mutations and Environmental Factors: Japan Molecular Epidemiology for Lung Cancer Study. J Clin Oncol 34: 2247-2257.

69. Shi Y, Au JS, Thongprasert S, Srinivasan S, Tsai CM, et al. (2014) A prospective, molecular epidemiology study of EGFR mutations in Asian patients with advanced non-small-cell lung cancer of adenocarcinoma histology (PIONEER). J Thorac Oncol 9:154-162.
70. Mitsudomi T, Kosaka T, Yatabe Y (2006) Biological and clinical implications of EGFR mutations in lung cancer. Int J Clin Oncol 11: 190-198.[Crossref]

71. Mok TS, Wu YL, Thongprasert S, Yang CH, Chu DT, et al. (2009) Gefitinib or carboplatin-paclitaxel in pulmonary adenocarcinoma. N Engl J Med 361: 947-957. [Crossref]

72. Wu YL, Zhou C, Hu CP, Feng J, Lu S, et al. (2014) Afatinib versus cisplatin plus gemcitabine for first-line treatment of Asian patients with advanced non-small-cell lung cancer harbouring EGFR mutations (LUX-Lung 6): an open-label, randomised phase 3 trial. Lancet Oncol 15: 213-222.

73. Bria E, Milella M, Cuppone F, Novello S, Ceribelli A, et al. (2011) Outcome of advanced NSCLC patients harboring sensitizing EGFR mutations randomized to EGFR tyrosine kinase inhibitors or chemotherapy as first-line treatment: a meta-analysis. Ann Oncol 22: 2277-2285.

74. Lee CK, Brown C, Gralla RJ, Hirsh V, Thongprasert S, et al. (2013) Impact of EGFR inhibitor in non-small cell lung cancer on progression-free and overall survival: a metaanalysis. J Natl Cancer Inst 105: 595-605.[Crossref]

75. Niu FY, Wu YL (2014) Novel agents and strategies for overcoming EGFR TKIs resistance. Exp Hematol Oncol 3: 2.[Crossref]

76. Kosaka T, Yatabe Y, Endoh H, Yoshida K, Hida T, et al. (2006) Analysis of epiderma growth factor receptor gene mutation in patients with non-small cell lung cancer and acquired resistance to gefitinib. Clin Cancer Res 12: 5764-5769.

77. Wang S, Cang S, Liu D (2016) Third-generation inhibitors targeting EGFR T790M mutation in advanced non-small cell lung cancer. J Hematol Oncol 9: 34.[Crossref]

78. Walter AO, Sjin RT, Haringsma HJ, Ohashi K, Sun J, et al. (2013) Discovery of a mutant-selective covalent inhibitor of EGFR that overcomes T790M-mediated resistance in NSCLC. Cancer Discov3:1404-1415.

79. Cross DA, Ashton SE, Ghiorghiu S, Eberlein C, Nebhan C, et al. (2014) AZD9291, an irreversible EGFR TKI, overcomes T790M-mediated resistance to EGFR inhibitors in lung cancer. Cancer Discov 4: 1046-1061.[Crossref]

80. Mok TS, Wu YL, Ahn MJ, Garassino MC, Kim H, et al. (2017) Osimertinib or Platinum-Pemetrexed in EGFR T790M-Positive Lung Cancer. N Engl J Med 376: 629640.[Crossref]

81. Soda M, Choi YL, Enomoto M, Takada S, Yamashita Y, et al. (2007) Identification of the transforming EML4-ALK fusion gene in non-small-cell lung cancer. Nature 448: 561-566.[Crossref]

82. Takeuchi K, Choi YL, Togashi Y, Soda M, Hatano S, et al. (2009) KIF5B-ALK, a novel fusion oncokinase identified by an immunohistochemistry-based diagnostic system for ALK-positive lung cancer. Clin Cancer Res 15: 3143-3149.

83. Rodig SJ, Mino-Kenudson M, Dacic S, Yeap BY, Shaw A, et al. (2009) Unique clinicopathologic features characterize ALK-rearranged lung adenocarcinoma in the western population. Clin Cancer Res 15: 5216-5223.

84. Shaw AT, Yeap BY, Mino-Kenudson M, Digumarthy SR, Costa DB, et al. (2009) Clinical features and outcome of patients with non-small-cell lung cancer who harbor EML4-ALK. J Clin Oncol 27: 4247-4253.[Crossref]

85. Solomon B, Varella-Garcia M, Camidge DR (2009) ALK gene rearrangements: a new therapeutic target in a molecularly defined subset of non-small cell lung cancer. $J$ Thorac Oncol 4: 1450-1454.[Crossref]

86. Inamura K, Takeuchi K, Togashi Y, Nomura K, Ninomiya H, et al. (2008) EML4-ALK fusion is linked to histological characteristics in a subset of lung cancers. $J$ Thorac Oncol 3: 13-17.

87. Shaw AT, Kim DW, Nakagawa K, Seto T, Crinó L, et al. (2013) Crizotinib versus chemotherapy in advanced ALK-positive lung cancer. $N$ Engl J Med 368: 2385-2394. [Crossref]

88. Matikas A, Kentepozidis , Georgoulias V, Kotsakis A (2016) Management of Resistance to Crizotinib in Anaplastic Lymphoma Kinase-Positive Non-Small-cell Lung Cancer. Clin Lung Cancer 17: 474-482.[Crossref]

89. Katayama R, Shaw AT, Khan TM, Mino-Kenudson M, Solomon BJ, et al. (2012) Mechanisms of acquired crizotinib resistance in ALK-rearranged lung Cancers. Sci Transl Med 4: 120ra17.[Crossref]

90. Choi YL, Soda M, Yamashita Y, Ueno T, Takashima J, et al. (2010) EML4-ALK mutations in lung cancer that confer resistance to ALK inhibitors. N Engl J Med 363 : 1734-1739.[Crossref]

91. Crino L, Ahn MJ, De Marinis F, Groen HJ, Wakelee H, et al. (2016) Multicenter Phase II Study of Whole-Body and Intracranial Activity with Ceritinib in Patients With ALK- 
Rearranged Non-Small-Cell Lung Cancer Previously Treated With Chemotherapy and Crizotinib: Results From ASCEND-2. J Clin Oncol 34: 2866-2873.

92. Soria JC, Tan DS, Chiari R, Wu YL, Paz-Ares L, et al. (2017) First-line ceritinib versus platinum-based chemotherapy in advanced ALK-rearranged non-small-cell lung cancer (ASCEND-4): a randomised, open-label, phase 3 study. The Lancet 389: 917-929.

93. Harvey JJ (1964) An unidentified virus which causes the rapid production of tumours in mice. Nature 204: 1104-1105.[Crossref]

94. Santos E, Martin-Zanca D, Reddy EP, Pierotti MA, Della Porta G, et al. (1984) Malignant activation of a K-ras oncogene in lung carcinoma but not in normal tissue of the same patient. Science 223:661-664.

95. Vojtek AB, Der CJ (1998) Increasing complexity of the Ras signaling pathway. J Biol Chem 273: 19925-19928.[Crossref]

96. Riely GJ, Kris MG, Rosenbaum D, Marks J, Li A, et al. (2008) Frequency and distinctive spectrum of KRAS mutations in never smokers with lung adenocarcinoma. Clin Cancer Res 14: 5731-5734.

97. Ahrendt SA, Decker PA, Alawi EA, Zhu Yr YR, Sanchez-Cespedes M, et al. (2001) Cigarette smoking is strongly associated with mutation of the K-ras gene in patients with primary adenocarcinoma of the lung. Cancer 92: 1525-1530.

98. Broet P, Dalmasso C, Tan EH, Alifano M, Zhang S, et al. (2011) Genomic profiles specific to patient ethnicity in lung adenocarcinoma. Clin Cancer Res 17: 3542-3550.

99. Reinersman JM, Johnson ML, Riely GJ, Chitale DA, Nicastri AD, et al. (2011) Frequency of EGFR and KRAS mutations in lung adenocarcinomas in African Americans. J Thorac Oncol 6: 28-31.[Crossref]

100. Janne PA, Shaw AT, Pereira JR, Jeannin G, Vansteenkiste J, et al. (2013) Selumetinib plus docetaxel for KRAS-mutant advanced non-small-cell lung cancer: a randomised, multicentre, placebo-controlled, phase 2 study. Lancet Oncol 14: 38-47.

101. Mascaux C, Iannino N, Martin B, Paesmans M, Berghmans T, et al. (2005) The role of RAS oncogene in survival of patients with lung cancer: a systematic review of the literature with meta-analysis. Br J Cancer 92 : 131-139.[Crossref]

102. Brahmer J, Reckamp KL, Baas P, Crino L, Eberhardt WE, et al.(2015) Nivolumab versus Docetaxel in Advanced Squamous-Cell Non-Small-Cell Lung Cancer. $N$ Engl J Med 373:123-135.

103. Borghaei H, Paz-Ares L, Horn L, Spigel DR, Steins M, et al. (2015) Nivolumab versus Docetaxel in Advanced Nonsquamous Non-Small-Cell Lung Cancer. $N$ Engl J Med 373: 1627-1639.[Crossref]

104. Herbst RS, Baas P, Kim DW, Felip E, Perez-Gracia JL, et al. (2016) Pembrolizumab versus docetaxel for previously treated, PD-L1-positive, advanced non-small-cell lung cancer (KEYNOTE-010): a randomised controlled trial. Lancet 387: 1540-1550.

105. Reck M, RodrÃguez-Abreu D, Robinson AG, Hui R, CsÅ'szi T, et al. (2016) Pembrolizumab versus Chemotherapy for PD-L1-Positive Non-Small-Cell Lung Cancer. N Engl J Med 375: 1823-1833.[Crossref]

106. Langer CJ, Gadgeel SM, Borghaei H, Papadimitrakopoulou VA, Patnaik A, et al (2016) Carboplatin and pemetrexed with or without pembrolizumab for advanced, non-squamous non-small-cell lung cancer: a randomised, phase 2 cohort of the openlabel KEYNOTE-021 study. Lancet Oncol 17: 1497-1508.

107. Pennell NA (2015) Understanding the Rationale for Immunotherapy in Non-Small Cell Lung Cancer. Semin Oncol 42 Suppl 2: S3-10.[Crossref]

108. Zhou GW, Xiong Y, Chen S, Xia F, Li Q, et al. (2016) Anti-PD-1/PD-L1 antibody therapy for pretreated advanced nonsmall-cell lung cancer: A meta-analysis of randomized clinical trials. Medicine 95: e4611.

Copyright: $@ 2017$ Conterato AJ. This is an open-access article distributed under the terms of the Creative Commons Attribution License, which permits unrestricted use, distribution, and reproduction in any medium, provided the original author and source are credited. 